\title{
Corrosion behavior of new quaternary ZrNbTiAl alloys in simulated physiological solution using electrochemical techniques and surface analysis methods
}

\author{
R. Chelariu ${ }^{1}$, L.C. Trinca ${ }^{2, *}$, C. Munteanu ${ }^{3}$, G. Bolat ${ }^{4}$, D. Sutiman ${ }^{1}$, D. Mareci, ${ }^{4}$, R.M. Souto ${ }^{5,6, *}$ \\ ${ }^{1}$ Technical University “Gheorghe Asachi” of Iasi, Faculty of Materials Science, D. Mangeron, Iasi, \\ 700050, Romania \\ 2 “Ion Ionescu de la Brad” University of Agricultural Science and Veterinary Medicine, Faculty of \\ Horticulture, Science Department, 3, Mihail Sadoveanu Alley, Iaşi, 700490, Romania \\ 3 Technical University “Gheorghe Asachi” of Iasi, Faculty of Mechanical Engineering, D. Mangeron, \\ Iasi, 700050, Romania \\ ${ }^{4}$ Technical University “Gheorghe Asachi” of Iasi, Faculty of Chemical Engineering and Environmental \\ Protection, D. Mangeron, Iasi, 700050, Romania \\ ${ }^{5}$ Department of Physical Chemistry, Universidad de La Laguna, E-38200 La Laguna, Tenerife, Canary \\ Islands, Spain \\ ${ }^{6}$ Institute of Material Science and Nanotechnology, Universidad de La Laguna, E-38200 La Laguna, \\ Tenerife, Canary Islands, Spain.
}

\begin{abstract}
The potential biomedical application of three new quaternary Zr alloys, namely Zr6Ti15Nb4Al, Zr32Ti15Nb4Al, and Zr49Ti15Nb4Al, was evaluated in vitro using electrochemical methods complemented with surface analysis of corrosion resistance. Cyclic potentiodynamic polarization (CCP) and electrochemical impedance spectroscopy (EIS) tests were performed in Ringer's solution at $37{ }^{\circ} \mathrm{C}$. The electrochemical behavior of the ZrTiNbAl quaternary alloys was consistent with the formation of passivating oxide films on the surfaces of these materials. Localized breakdown of the oxide layer occurred on Zr6Ti15Nb4Al and Zr32Ti15Nb4Al alloys subjected to positive anodic polarization, a feature confirmed by scanning electron microscopy (SEM) on retrieved samples. The Zr49Ti15Nb4Al alloy, which had the highest titanium (49 wt.\%) content, exhibited a larger passive range in the polarization curve and was immune to localized corrosion breakdown in a simulated physiological solution for the range of polarizations that can occur in the human body.
\end{abstract}

Keywords: ZrTiNbAl quaternary alloys; Biomaterial; Corrosion resistance; Ringer’s physiological solution; Electrochemical techniques. 


\section{Introduction}

Zirconium has mainly been used as a structural material in nuclear applications due to its low neutron absorption. Recently, zirconium-based materials have received renewed attention as structural materials for aerospace, chemical and biomedical applications due to their corrosion resistance and wear properties [1]. Despite early in vivo studies demonstrating favorable bone tissue reactions similar to titanium after short-term contact with bone [2], little research has been carried out into the use of zirconium-based materials as biomaterials [3-6]. It is only in recent years that the potential of these materials to meet the requirements for medical applications has been explored [7-17]. For zirconiumbased materials to be employed as structural materials for permanent implants in contact with bone tissue, mutual interactions at the implant-tissue interface must be characterized [18,19]. Among them, the corrosion processes suffered by metallic materials in the chemically-aggressive medium of the human body are of special importance $[18,19]$.

Zirconium belongs to the class of the valve metals, a group of metals characterized by their spontaneous chemical interaction with oxidizing environments that leads to the formation of surface oxide films [20-22]. In biomedical applications, these films determine the physicochemical and biological processes that occur at the implant/tissue interface $[1,18,19,23]$, and thus greatly determine the biocompatibility of such materials [24]. Indeed, the formation and stability of surface oxide films was a major criterion to select these metallic materials for biomedical application. However, in vitro and in vivo studies have evidenced the release of metal ions from these oxidized films [18,19,24]. Such corrosion of permanent metal implants in the environment of the human body is affected by the chemical composition, structure, and physicochemical properties of surface oxide films, which are subject to change over the lifetime of the implants.

The human body contains about 60 wt.\% water distributed as both extracellular and intracellular fluid [25]. Most of the extracellular fluid is plasma, an interstitial fluid which contains water, various ions (mainly $\mathrm{Na}^{+}, \mathrm{K}^{+}, \mathrm{Ca}^{2+}, \mathrm{Mg}^{2+}, \mathrm{Cl}^{-}$and $\mathrm{HCO}_{3}^{-}$), and proteins [25-27]. When bodily fluid imbalance occurs, for any clinical reason, fluid therapy is performed using different solutions of crystalloids or colloids with plasma-like electrolyte compositions [28,29]. Among them, both isotonic saline and Ringer's solutions are used for this purpose, the latter being closer to plasma composition [25-30]. This is the reason behind the frequent use of any of these solutions as a corrosive environment for preclinical testing of metallic materials designed for medical applications [14,31,32]. They are

highly oxygenated saline electrolytes containing chloride ions, which are known as one of the most aggressive ions to metals $[33,34]$. 
The corrosion behavior of $\mathrm{Zr}$ and its alloys was extensively investigated in relation to their uses in nuclear and chemical industries [35,36]. Zirconium is characterized by a strong affinity for oxygen and the formation of oxides and other compounds with valence +4 . This feature allows the metal to be passivated, even in highly reducing media [37], such as strong reducing acids [38]. However, the formation of protective oxide films on $\mathrm{Zr}$ is hampered in certain aqueous media such as oxidizing chlorine solutions [37]. In addition, $\mathrm{Zr}$ is susceptible to pitting in chloride-containing aqueous solutions [39]. Although zirconium and titanium chemistries have numerous similarities, there are important differences with respect to their corrosion resistance in chloride containing environments. The passive film on zirconium based materials is not very stable in these media compared to titanium based materials, and passive film breakdown has been observed under oxidizing conditions [7,31,40]. Since a procedure to improve the corrosion behavior of metals in a given environment is achieved through the proper selection of alloying elements, our group performed a systematic investigation into the corrosion behavior of three binary ZrTi alloys in simulated body fluids [31,41-46]. A key finding was that the stability of the passive films on binary ZrTi alloys improved with higher Ti content [31,41-46]. Simultaneously, the behavior of new Zr-Nb, Zr-Ta, Zr-Nb-Ti, Zr-Nb-Ta, Zr-Nb-Mo, Zr-Nb-W alloy combinations were investigated by other groups with the same aim of improving the corrosion resistance of Zr-based materials [10,14,47]. Thus, it was demonstrated that the corrosion resistance of Zircalloy-2 alloy in $1 \mathrm{M} \mathrm{H}_{2} \mathrm{SO}_{4}$ was improved after the implantation of $\mathrm{Al}$ ions under certain process conditions [48]. Finally, since metallic materials for structural biomedical application must meet additional requirements in terms of their mechanical and magnetic properties, in addition to corrosion resistance, new alloys from the Zr-Nb, Zr-Sn, Zr-Ta, Zr-Si, Zr-Mo, Zr-Mo-Ti, Zr-Nb-Ti, Zr-Nb-Ti-MoSn systems have also been proposed [7,10-12,16,17,49-51].

In this context, this work aims to characterize the corrosion behavior of three new alloys of the Zr-Ti-Nb-Al system in Ringer's solution at $37^{\circ} \mathrm{C}$ by electrochemical techniques complemented with surface analysis methods.

\section{Materials and Methods}

\subsection{Materials}

Three new quaternary ZrTiNbAl alloys were synthesized through repetitive melting of primary ingots. Cylindrical ingots $30 \mathrm{~mm}$ in diameter and $70 \mathrm{~mm}$ in length were obtained using the electron beam drip melting method and an electron beam furnace EMO 80 (ZIROM SA, Giurgiu, Romania). Samples of $14 \mathrm{~mm}$ in diameter and $5 \mathrm{~mm}$ in length were cut from the ingots using conventional 
machining procedures for both electrochemical tests and microstructure analysis. The chemical compositions of the ZrTiNbAl alloys were determined by energy-dispersive spectroscopy analysis (VegaTescan LMH II, Quantax EDS) and are given in Table 1. It can be seen that the Zr6Ti15Nb4Al alloy has the highest content of Zr (in wt.\%), the lowest Ti content, and similar Nb and Al content. The other two alloys, namely Zr32Ti15Nb4Al and Zr49Ti15Nb4Al, have similar percentages of $\mathrm{Nb}$ and $\mathrm{Al}$, but inverse percentages of $\mathrm{Zr}$ and Ti. For purposes of comparison, corrosion behavior is discussed in terms of the $\mathrm{Zr} / \mathrm{Ti}$ ratio in alloys.

\subsection{Surface analysis}

Samples for microscopy and XRD analysis were abraded with emery papers of different grits, followed by polishing using alumina suspensions $(0.3 \mu \mathrm{m}$ and $0.02 \mu \mathrm{m})$ to achieve a mirror smooth appearance. Finally, the samples were etched using Kroll's reagent. To characterize the microstructure of the alloys, an inverted metallographic microscope (XJP 6A model, Material Plus software, Qualitest, Ft. Lauderdale, FL, USA) and a scanning electron microscope (VegaTescan LMH II, Quantax EDS, Bruker Nano Analytics, Berlin, Germany) were used.

XRD patterns of alloys were recorded using a PANalytical X'Pert PRO MPD diffractometer with $\mathrm{Cu}$ cathode (PANalytical, Almelo, The Netherlands). The XRD patterns were interpreted with X'pert HighScore Plus software and ICDD-PDF-4+ database.

\subsection{Electrochemical tests}

Prior to testing, the ZrTiNbAl alloys were mechanically abraded with emery papers of different grits down to 2000 grit, followed by polishing with $1 \mu \mathrm{m}$ alumina suspension, ultrasonically cleaning in deionized water, and finally drying in the open air. The electrochemical tests were performed in a glass corrosion flow cell kit (C145/170, Radiometer, Neuilly-Plaisance, France) containing $150 \mathrm{~mL}$ of Ringer's solution (NaCl: $8.6 \mathrm{~g} \mathrm{~L}^{-1}$; KCl: $0.3 \mathrm{~g} \mathrm{~L}^{-1}$; $\mathrm{CaCl}_{2}$ : $0.48 \mathrm{~g} \mathrm{~L}^{-1}$; $\mathrm{pH}=6.9$ ). The ZrTiNbAl samples were connected as the working electrode, a saturated calomel electrode was used as the reference electrode, and a platinum coil as the counter electrode. The temperature of the electrochemical cell was maintained at $37 \pm 0.1{ }^{\circ} \mathrm{C}$. The electrochemical measurements were performed using a potentiostat PARSTAT 4000 (Princeton Applied Research, Princeton, NJ, USA). The instrument was controlled by a personal computer and VersaStudio software. Potentiodynamic polarization and electrochemical impedance spectroscopy (EIS) were employed. 
Electrochemical impedance spectra were measured over a frequency range extending from 100 $\mathrm{kHz}$ to $1 \mathrm{mHz}$ using a $10 \mathrm{mV}$ amplitude AC voltage signal (peak to peak). The EIS tests were recorded at the open circuit potential developed by the samples after $1 \mathrm{~h}, 24 \mathrm{~h}$ (1 day), and $168 \mathrm{~h}$ (7 days) of immersion in the Ringer's solution. The OCP value monitored at each time was fixed using the potentiostatic unit of the electrochemical interface, so as to avoid possible floating during acquisition of the impedance spectrum. EIS tests were obtained to evaluate the characteristics of passive films formed on the surface of the alloys under investigation. Analysis of the spectra was performed in terms of equivalent circuit (EC) fitting using ZSimpWin software.

The potentiodynamic polarization tests were initiated after $168 \mathrm{~h}$ (7 days) immersion of the samples in the Ringer's solution. The tests were conducted by scanning the potential, at the rate of 1 $\mathrm{mV} \mathrm{s}^{-1}$, from $-1.0 \mathrm{~V}_{\mathrm{SCE}}$ up to $+1.0 \mathrm{~V}_{\mathrm{SCE}}$, followed by potential reversal down to $+0.0 \mathrm{~V}_{\mathrm{SCE}}$, in order to explore the occurrence of pitting. Standard techniques were used to extract the zero current potential ( $\left.E_{\text {corr }}\right)$, and the corrosion current density $\left(j_{\text {corr }}\right)$, namely the application of Tafel analysis for a range of $\pm 100 \mathrm{mV}$ around the open circuit potential. From the measured potentiodynamic polarization curves,

the passive current density (jpass) was also determined. For each electrochemical test, three specimens were monitored, and the analysis of variance (ANOVA) was performed using a Tukey post hoc test ( $p$ $<0.05$ ). Their average results are given together with the corresponding standard deviation (reported in brackets). After potentiodynamic polarization tests, the surfaces of the retrieved samples were inspected by scanning electron microscopy to visualize localized corrosion processes (Quanta 200 3D, FEI, Hillsboro, OR, USA).

\section{Results and Discussion}

\subsection{Surface analysis}

Figure 1 shows the optical microstructures of the quaternary ZrNbTiAl alloys. Polygonal $\beta$ phase grains are observed for all alloys, closely resembling those reported for ternary ZrNbTi alloys by Nie et al. [12]. The average grain size and average (stdev) values were determined with the Material Plus software providing 538 (217) $\mu \mathrm{m}$ for Zr6Ti15Nb4Al, 497 (126) $\mu \mathrm{m}$ for Zr32Ti15Nb4Al, and 489 (242) $\mu \mathrm{m}$ for Zr49Ti15Nb4Al. These grain sizes (hundreds of micrometers) are specific for as-cast microstructures of alloys synthesized by electron beam melting.

The elemental maps obtained using EDS in Figure 2 show fairly even distribution of the alloying elements in the ZrNbTiAl quaternary alloys. The small color changes between the maps for the chosen magnification arise exclusively from the variable $\mathrm{Zr} / \mathrm{Ti}$ ratio in the alloys. 
Figure 3 shows the XRD patterns for all investigated alloys. They contain solid solutions based on $\beta$-Zr or $\beta$-Ti phases, which are indicated by the well-resolved peaks corresponding to the planes (110), (200), (211), (220) and (310). The predominant $\beta$ phase observed here was also reported for ternary Zr-Nb-Ti alloys [12]. Moreover, Zr6Ti15Nb4Al presents a small amount of solid solution based on the $\alpha-Z r$ phase, which is revealed by some additional small peaks related to the $\alpha-\operatorname{Zr}(101)$ plane at $40^{\circ}$, the $\alpha-\operatorname{Zr}(102)$ plane at app. $45^{\circ}$, and the $\alpha-\operatorname{Zr}(202)$ plane at $77^{\circ}$. Furthermore, the following lattice parameters were evaluated from XRD data: i) $\alpha$-Zr solid solution (hcp), $a=3.252 \AA, c=5.041 \AA, c / a=$ 1.5502, and $\beta$-Zr solid solution (bcc), $a=3.484 \AA$, for Zr6Ti15Nb4Al; ii) $\beta$-Zr solid solution (bcc), $a=$ $3.3985 \AA$, for Zr32Ti15Nb4Al; iii) $\beta$-Ti solid solution (bcc), $a=3.3507 \AA$, for Zr49Ti15Nb4Al.

\subsection{Electrochemical characterization}

Potentiodynamic polarization curves for ZrNbTiAl alloys recorded after $168 \mathrm{~h}$ (7 days) immersion in Ringer's solution at $37^{\circ} \mathrm{C}$ present a typical active-passive characteristic, moving directly from the active region to a passive region as shown in Figure 4. The Tafel analysis performed on the anodic and cathodic branches of the polarization plots yielded the values for the zero current potential $\left(E_{\text {corr }}\right)$ and the corrosion current density ( $\left.j_{\text {corr }}\right)$ listed in Table 2 . The potential reversal at +1.0 VSCE resulted in the observation of positive hysteresis loops in the potentiodynamic polarization curves for Zr6Ti15Nb4Al and Zr32Ti15Nb4Al, indicating that these materials were susceptible to localized corrosion (see Figure 4). The hysteresis loop can be used to obtain experimental data on localized corrosion. Thus, the susceptibility to localized corrosion of a material can be expressed both in terms of the area covered by the hysteresis loop $\left(Q_{\text {hyst }}\right)$, and in terms of the breakdown $\left(E_{\mathrm{bp}}\right)$ and repassivation $\left(E_{\mathrm{rp}}\right)$ potentials relative to the corresponding corrosion potential value $\left(E_{\text {corr }}\right)$. From inspection of Table 2, it is observed that the Zr6Ti15Nb4Al alloy exhibited a larger area of the hysteresis loop and a more negative breakdown potential value than the Zr32Ti15Nb4Al alloy. In addition, the Zr6Ti15Nb4Al alloy presented the narrowest potential range for passivity. These features indicate that this alloy had the highest susceptibility to localized corrosion. In contrast, the Zr49Ti15Nb4Al alloy showed negative hysteresis in the cyclic polarization curves recorded in Ringer's solution, indicating that this alloy was resistant to localized corrosion in this environment.

Electrochemical impedance spectroscopy (EIS) measurements were performed under open circuit potential conditions for various different immersion times in Ringer's solution at $37{ }^{\circ} \mathrm{C}$ up to 168 h (7 days). The Bode plots depicted in Figure 5 show two time constants in the impedance spectra at all times. The EIS spectra were analyzed in terms of the equivalent circuit (EC) shown in Figure 6, 
corresponding to a duplex structure formed by an outer porous and more compact inner layers. This EC is typically employed to described the passive films formed on titanium [52,53] and zirconium [41,54] based materials. Constant phase elements (CPE) were used instead of pure capacitances because of the non-ideal capacitive response due to the distributed relaxation feature of the passive oxide films [55]. Table 3 shows the results of the fits, while the simulated impedance spectra obtained using these parameters are shown by solid lines in Figure 5. The components $R_{\mathrm{ct}}$ and $Q_{\mathrm{dL}}$ account for the electrochemical processes at the passive layer/solution interface, and they determine the impedance behavior in the high frequency range of the spectrum. The capacitance values associated with $Q_{\mathrm{dL}}$ are typical of those related to the double layer capacitance of passive oxide layers in all cases [45-48]: further confirmation for the assignment of the $R_{\mathrm{pL}}$ and $Q_{\mathrm{pL}}$ parameters to describe the properties of the passive layer. In general, a very good agreement was reached between the fitted data and the experimental data for the ZrNbTiAl samples ( $\chi^{2}$ values between $10^{-4}$ and $\left.10^{-5}\right)$.

\subsection{SEM analysis of retrieved surfaces from electrochemical tests}

Figure 7 shows SEM micrographs of the retrieved ZrTiNbAl alloys after completing the potentiodynamic polarization tests in Ringer's solution given in Figure 4. Passive layer breakdown and the onset of localized corrosion occurred in the case of Zr6Ti15Nb4Al and Zr32Ti15Nb4Al alloys (cf. Figure 7a-b). Although corrosion pits were observed on the surface of both alloys, pits of micrometric dimensions were observed in the case of the alloy Zr32Ti15Nb4Al, certainly on a smaller scale than for Zr6Ti15Nb4Al. On the other hand, no localized attack was observed in the case of the Zr49Ti15Nb4Al alloy (see micrograph in Figure 7c). The passive films formed on the surface of this alloy effectively protected the underlying metal matrix even at anodic polarization of $+1.0 \mathrm{VSCE}$, higher than polarization values ever measured in the human body [56]. SEM micrographs of the retrieved ZrNbTiAl samples after the electrochemical tests in Ringer's solution were consistent with the conclusions derived from the inspection of the potentiodynamic polarization curves shown in Figure 4.

\subsection{Comments on the corrosion resistance of passive layers formed on quaternary ZrNbTiAl alloys}

The corrosion behavior of valve metals depends on the protectiveness of their passive film, which is, in turn, determined by its chemical composition, its level of crystallinity, and the crystallography of the surface oxide film. Using XPS analysis, Hanawa et al. [23,57] found that the

oxide film formed on commercial pure (cp)-Ti contains $\mathrm{Ti}^{2+}, \mathrm{Ti}^{3+}$, and $\mathrm{Ti}^{4+}$. That is, titanium oxide films result from a sequence of consecutive oxidation reactions: 


$$
\begin{aligned}
& \mathrm{Ti}+\mathrm{H}_{2} \mathrm{O}=\mathrm{TiO}+2 \mathrm{H}^{+}+2 e^{-} \\
& 2 \mathrm{TiO}+\mathrm{H}_{2} \mathrm{O}=\mathrm{Ti}_{2} \mathrm{O}_{3}+2 \mathrm{H}^{+}+2 e^{-} \\
& \mathrm{Ti}_{2} \mathrm{O}_{3}+\mathrm{H}_{2} \mathrm{O}=2 \mathrm{TiO}_{2}+2 \mathrm{H}^{+}+2 e^{-}
\end{aligned}
$$

Analogously, the oxide films on Zr usually present a layered structure determined by the stoichiometry of different oxides that grow from the metallic substrate toward the outer surface in a sequence of increasing oxidation numbers, namely $\mathrm{Zr}_{2} \mathrm{O} / \mathrm{ZrO}_{2} \mathrm{Zr}_{2} \mathrm{O}_{3} / \mathrm{ZrO}_{2}$ [1,58]:

$$
\begin{aligned}
& 2 \mathrm{Zr}+\mathrm{H}_{2} \mathrm{O}=\mathrm{Zr}_{2} \mathrm{O}+2 \mathrm{H}^{+}+2 e^{-} \\
& \mathrm{Zr}_{2} \mathrm{O}+\mathrm{H}_{2} \mathrm{O}=2 \mathrm{ZrO}+2 \mathrm{H}^{+}+2 e^{-} \\
& 2 \mathrm{ZrO}+\mathrm{H}_{2} \mathrm{O}=\mathrm{Zr}_{2} \mathrm{O}_{3}+2 \mathrm{H}^{+}+2 e^{-} \\
& \mathrm{Zr}_{2} \mathrm{O}_{3}+\mathrm{H}_{2} \mathrm{O}=2 \mathrm{ZrO}_{2}+2 \mathrm{H}^{+}+2 e^{-}
\end{aligned}
$$

Using Raman spectroscopy, Gomez Sanchez et al. [59] and Farina et al. [15] found that the oxide film formed spontaneously on $\mathrm{Zr}$ in the air mainly has a tetragonal structure of $\mathrm{ZrO}_{2}$, whereas the oxide films formed on $\mathrm{Zr}$ and $\mathrm{Zr}-2.5 \mathrm{Nb}$ alloy by anodization present mainly a monoclinic structure of $\mathrm{ZrO}_{2}$. In the case of the anodized samples from $\mathrm{Zr}$ and $\mathrm{Zr}-2.5 \mathrm{Nb}$ alloy, the $\mathrm{ZrO}_{2}$ monoclinic film incorporated a new phase identified as a Zr phosphate demonstrating the incorporation of phosphate ions from the electrolyte $[15,58,59]$. Although experimental data on the crystallography of passive films on Zr-based materials are scarce, from these few antecedents it can be argued that the crystallographic structure of such oxide films depends strongly on the oxidizing medium employed. Bastl et al. [58], using angle-resolved X-ray photoelectron spectroscopy (ARXPS), have shown that oxide films grown on $\mathrm{Zr}-1 \mathrm{Nb}$ alloy contain four oxidation states regardless of the oxidizing medium (namely oxygen, water, hydrogen peroxide). These characteristics are consistent with a layered structure of oxide films. Using XPS analysis, Gomez Sanchez et al. [59] showed the occurrence of different oxidation states on Zr oxidized in air, although there were cases where the suboxides were not identified $[23,59,60]$. 
The XPS spectra of both cp-Ti and cp-Zr contain three peaks in the O1s region, which correspond to oxide, $\mathrm{O}^{2-}$, hydroxide or hydroxyl groups, $\mathrm{OH}^{-}$, and hydrate and/or adsorbed $\mathrm{H}_{2} \mathrm{O}$, but less $\mathrm{OH}^{-}$than occurs in the oxide film on cp-Zr [23,57]. Satpati et al. [40] found similar results for XPS spectra of the oxide film on Zircaloy-2 after various different polarizations in $5 \% \mathrm{NaCl}$ solution. In addition, it was observed that the values of the $\mathrm{OH}^{-} / \mathrm{O}^{2-}$ ratio decreased as the polarization potential increased, as well as that $\mathrm{Cl}^{-}$was incorporated in the passive film, demonstrated by the appearance of a chloride peak in the XPS spectra [40]. Hanawa et al. [61] used XPS to investigate changes in oxide films formed on Ti, Zr and four Ti-Zr alloys (Ti-25 wt.\% Zr, Ti-50 wt.\% Zr, Ti-60 wt.\% Zr, Ti-75 wt.\% Zr) after different immersion times in a simulated body fluid (SBF) at $25{ }^{\circ} \mathrm{C}$. Their findings demonstrated the influence of both the chemical composition of the metallic materials and the immersion times.

Alloying $\mathrm{Zr}$ with $\mathrm{Ti}$ is an established procedure to improve the corrosion resistance of this metal, especially in relation to pitting corrosion [62,63]. Thus, a Ti content in Zr greater than 10 wt.\% shifted positively the pitting potential in aqueous $\mathrm{HCl}$ solution, and for a $\mathrm{Ti}$ content greater than 50 wt.\%, the pitting potential reached values comparable to those of pure Ti [63]. It was proposed that the improvement of the pitting corrosion resistance was derived from the formation of $\mathrm{ZrTiO}_{4}$ for intermediate contents of $\mathrm{Ti}$ (up to 40 wt.\%), or $\mathrm{ZrTiO}_{4}$ and $\mathrm{TiO}_{2}$ for a $\mathrm{Ti}$ content of more than 50 wt.\% [63]. Recently, the same procedure has been adopted to improve the corrosion behavior of zirconium used in medical applications [31,41-46].

More recently, multi-component Zr-based alloys have been proposed as biomaterials, with $\mathrm{Nb}$ being one of the alloying elements investigated because of the high electrochemical stability of the $\mathrm{Nb}_{2} \mathrm{O}_{5}$ oxide [12]. The stable niobium oxides are formed according to the sequence [64]:

$$
\begin{aligned}
& \mathrm{Nb}+\mathrm{H}_{2} \mathrm{O}=\mathrm{NbO}+2 \mathrm{H}^{+}+2 e^{-} \\
& \mathrm{NbO}+\mathrm{H}_{2} \mathrm{O}=\mathrm{NbO}_{2}+2 \mathrm{H}^{+}+2 e^{-} \\
& 2 \mathrm{NbO}_{2}+\mathrm{H}_{2} \mathrm{O}=\mathrm{Nb}_{2} \mathrm{O}_{5}+2 \mathrm{H}^{+}+2 e^{-}
\end{aligned}
$$

In this context, the experimental results described in this work from electrochemical tests in simulated artificial solution have shown the beneficial effect of Ti content on resistance to pitting, especially when Ti content exceeds that of Zr. Such effects on corrosion behavior can be attributed to changes in the stoichiometry and crystallography of passive films, as described in cited literature. 


\section{Conclusions}

The results of the present study lead to the following conclusions:

1) Alloying $\mathrm{Zr}$ with $\mathrm{Nb}, \mathrm{Al}$ and especially $\mathrm{Ti}$, lead to the formation of oxide films on the surface of the metallic material that more efficiently withstand passive layer breakdown and the onset of localized forms of corrosion.

2) Quaternary ZrNbTiAl alloys are $\beta$-metastable titanium alloys with microstructures composed of polygonal $\beta$-phase grains of the order of hundreds of micrometers.

3) These alloys develop a two-layer passive oxide structure upon immersion in Ringer's solution for all exposures. Their corrosion resistance increases with decreasing $\mathrm{Zr} / \mathrm{Ti}$ ratio, and is also improved for longer exposures to the simulated physiological solution.

4) The Ti content of the $\mathrm{Zr}$ alloys is of great importance to improve localized corrosion behavior. A lower $\mathrm{Zr} / \mathrm{Ti}$ ratio than one leads to materials that do not undergo passivity breakdown and localized corrosion under the polarization conditions experienced by the human body.

\section{Acknowledgements}

This work was supported by grants from the Romanian National Authority for Scientific Research, CNCS-UEFISCDI, project number PN-II-ID-PCE-2011-3-0218, and from the Ministerio de Economía y Competitividad (MINECO, Madrid, Spain) and the European Regional Development Fund (Brussels, Belgium) under Grant Number CTQ2016-80522-P. Thanks are due to Zirom S.A. (Giurgiu, Romania) for kindly providing the ZrTiNbAl alloys used in this work.

\section{References}

1. N. Stojilovic, E.T. Bender, R.D. Ramsier, Surface chemistry of zirconium, Prog. Surf. Sci. 78 (2005) 101-184.

2. T. Albrektsson, H.A. Hansson, B. Ivarsson, Interface analysis of titanium and zirconium bone implants, Biomaterials 6 (1985) 97-101.

3. K.M. Sherepo, A.B. Parfenov, I.S. Zusmanovich, Application of zirconium alloys to endoprostheses and osteosynthesis appliances, Biomed. Eng. 27(5) (1992) 238-240. 
4. C.B. Johansson, A. Wennerberg, T. Albrektsson, Quantitative comparison of screw-shaped commercially pure titanium and zirconium implants in rabbit tibia, J. Mater. Sci: Mater. Med. 5 (1994) 340-344.

5. Y.H. Yun, V.T. Turitto, K.P. Daigle, P. Kovacs, J.A. Davidson, S.M. Slack, Initial hemocompatibility studies of titanium and zirconium alloys: Prekallikrein activation, fibrinogen adsorption, and their correlation with surface electrochemical properties, J. Biomed. Mater Res. 32 (1996) 77-85.

6. P. Thomsen, C. Larsson, L.E. Ericson, Structure of the interface between rabbit cortical bone and implants of gold, zirconium and titanium, J. Mater. Sci: Mater. Med. 8 (1997) 653-665.

7. F.Y. Zhou, K.J. Qiu, D. Bian, Y.F. Zheng, J.P. Lin, A Comparative in vitro study on biomedical Zr-2.5X (X = Nb. Sn) alloys, J. Mater. Sci. Technol. 30 (2014) 299-306.

8. R.M. Hoerth, M.R. Katunar, A. Gomez Sanchez, J.C. Orellano, S.M. Cere, W. Wagermaier, J. Ballarre, A comparative study of zirconium and titanium implants in rat: osseointegration and bone material quality, J. Mater. Sci: Mater. Med. 25 (2014) 411-422.

9. M.R. Katunar, A. Gomez Sanchez, J. Ballarre, M. Baca, C. Vottola, J.C. Orellano, H. Schell, G. Duffo, S. Cere, Can anodised zirconium implants stimulate bone formation? Preliminary study in rat model, Prog. Biomater. 3 (2014) 24, 10 pp.

10. G. Totea, D. Ionita, I. Demetrescu, M.M. Mitache, In vitro hemocompatibility and corrosion behavior of new Zr-binary alloys in whole human blood, Cent. Eur. J. Chem. 12 (2014) 796-803.

11. L. Nie, Y. Zhan, H. Liu, C. Tang, Novel $\beta$-type Zr-Mo-Ti alloys for biological hard tissue replacements, Mater. Design 53 (2014) 8-12.

12. L. Nie, Y. Zhan, T. Hu, X. Chen, C. Wang, $\beta$-Type Zr-Nb-Ti biomedical materials with high plasticity and low modulus for hard tissue replacements, J. Mech. Behav. Biomed. Mater. 29 (2014) 1-6.

13. P. Trivedi, S. Goel, S. Das, R. Jayaganthan, D. Lahiri, P. Roy, Biocompatibility of ultrafine grained zircaloy-2 produced by cryorolling for medical applications, Mater. Sci. Eng. C 46 (2015) 309-315.

14. F. Rosalbino, D. Maccio, G. Scavino, A. Saccone, Corrosion behavior of new ternary zirconium alloys as alternative materials for biomedical applications, Mater. Corros. 66 (2015) 1125-1132.

15. S.B. Farina, A. Gomez Sanchez, S. Ceré, Effect of surface modification on the corrosion resistance of Zr-2.5Nb as material for permanent implants, Procedia Mater. Sci. 8 (2015) 1166-1173. 
16. C. Li, Y. Zhan, W. Jiang, Zr-Si biomaterials with high strength and low elastic modulus, Mater. Design 32 (2011) 4598-4602.

17. C. Pang, Q. Wang, R. Zhang, Q. Li, X. Dai, C. Dong, P. K. Liaw, $\beta$ Zr-Nb-Ti-Mo-Sn alloys with low Young's modulus and low magnetic susceptibility optimized via a cluster-plus-glue-atom model, Mater. Sci. Eng. A 626 (2015) 369-374.

18. B. Kasemo, J. Lausmaa, Material-tissue interfaces: The role of surface properties and processes, Environ- Health Persp. 102 (Suppl 5) (1994) 41-45.

19. D.A. Puleo, A. Nanci, Understanding and controlling the bone-implant interface, Biomaterials 20 (1999) 2311-2321.

20. N.T.C. Oliveira, S.R. Biaggio, R.C. Rocha-Filho, N. Bocchi, Studies on the stability of anodic oxides on zirconium biocompatible alloys, J. Braz. Chem. Soc. 13 (2002) 463-468.

21. P. Schmuki, Self-organized oxide nanotube layers on titanium and other transition metals, in: P. Schmuki, S.Virtanen (Eds.), Electrochemistry at the Nanoscale, Springer, New York, NY, 2009, pp. 435-466.

22. A. Michaelis, Valve metal, Si and ceramic oxides as dielectric films for passive and active electronic devices, in: R.C. Alkire, D.M. Kolb, J. Lipkowski, P.N. Ross (Eds.), Advances in Electrochemical Science and Engineering, Vol. 10, Wiley-VCH, Weinheim, 2008, pp. 1-106.

23. Y. Tsutsumi, D. Nishimura, H. Doi, N. Nomura, T. Hanawa, Difference in surface reactions between titanium and zirconium in Hank’s solution, Mater. Sci. Eng. C 29 (2009) 1702-1708.

24. M. Geetha, A.K. Singh, R. Asokamani, A.K. Gogia, Ti based biomaterials, the ultimate choice for orthopaedic implants - A review, Prog. Mater. Sci. 54 (2009) 397-425.

25. B.R. Waterhouse, A.D. Farmery, The organization and composition of body fluids, Anaesth. Intensive Care 16 (2015) 467-472.

26. J.L. Gibson, I.D. Nesbitt, Fluid management, Surgery (Oxford) 34 (2016) 60-65.

27. I. Campbell, Physiology of fluid balance, Anaesth. Intensive Care 10 (2009) 593-596.

28. B. Guidet, N. Soni, G. Della Rocca, S. Kozek, B. Vallet, D. Annane, M. James, A balanced view of balanced solutions, Crit. Care 14 (2010) 325, 12 pp.

29. H. Buckley, R. Kishen, Crystalloids, colloids, blood, blood products and blood substitutes, Anaesth. Intensive Care 14 (2013) 255-260.

30. J. Boldt, Saline versus balanced hydroxyethyl starch: does it matter?, Transfus. Altern. Transfus. Med. 9 (2007) 189-197. 
31. R. Chelariu, D. Mareci, C. Munteanu, Preliminary electrochemical testing of some Zr-Ti alloys in 0.9\% NaCl solution, Mater. Corros. 64 (2013) 585-591.

32. F. Rosalbino, D. Maccio, P. Giannoni, R. Quarto, A. Saccone, Study of the in vitro corrosion behavior and biocompatibility of Zr-2.5Nb and Zr-1.5Nb-1Ta (at\%) crystalline alloys, J. Mater. Sci: Mater. Med. 22 (2011) 1293-1302.

33. N.T.C. Oliveira, S.R. Biaggio, R.C. Rocha-Filho, N. Bocchi, Electrochemical studies on zirconium and its biocompatible alloys Ti-50Zr at.\% and Zr-2.5Nb wt.\% in simulated physiologic media, J. Biomed. Mater. Res. A 74 (2005) 397-407.

34. D.C. Hansen, Metal corrosion in the human body: The ultimate bio-corrosion scenario, Interface 17 (2008) 31-34.

35. G.A. El-Mahdy, S.S. Mahmoud, Effect of different acid anions on kinetics of the formation and dissolution behavior of anodic zirconium oxide, Corrosion 54 (1998) 354-361.

36. A. Merati, B. Cox, Dissolution of anodic zirconium dioxide films in aqueous media, Corrosion 55 (1999) 388-396.

37. P.A. Schweitzer, Fundamentals of Metallic Corrosion: Atmospheric and Media Corrosion of Metals, CRC Press, Boca Raton, FL, 2007, pp. 577-579.

38. J. Fahey, D. Holmes, T.L. Yau, Evaluation of localized corrosion of zirconium in acidic chloride solutions, Corrosion 53 (1997) 54-61.

39. G.C. Palit, H.S. Gadiyar, Pitting corrosion of zirconium in chloride solution, Corrosion 43 (1987) 140-148.

40. A.K. Satpati, S.V. Phadnis, R.I. Sundaresan, Electrochemical and XPS studies and the potential scan rate dependent pitting corrosion behavior of Zircaloy-2 in 5\% NaCl solution, Corros. Sci, 48 (2005) 1445-1458.

41. G. Bolat, J. Izquierdo, J.J. Santana, D. Mareci, R.M. Souto, Electrochemical characterization of ZrTi alloys for biomedical applications. Electrochim. Acta 88 (2013) 447-456.

42. G. Bolat, J. Izquierdo, D. Mareci, D. Sutiman, R.M. Souto, Electrochemical characterization of ZrTi alloys for biomedical applications, Part 2: The effect of thermal oxidation, Electrochim. Acta 106 (2013) 432-439.

43. D. Mareci, D. Sutiman, R. Chelariu, F. Leon, S. Curteanu, Evaluation of the corrosion resistance of new ZrTi alloys by experiment and simulation with an adaptive instance-based regression model, Corros. Sci. 73 (2013) 106-122. 
44. D. Mareci, G. Bolat, R. Chelariu, D. Sutiman, C. Munteanu, The estimation of corrosion behaviour of ZrTi binary alloys for dental applications using electrochemical techniques, Mater. Chem. Phys. 141 (2013) 362-369.

45. D. Mareci, G. Bolat, A. Cailean, J.J. Santana, J. Izquierdo, R.M. Souto, Effect of acidic fluoride solution on the corrosion resistance of ZrTi alloys for dental implant application, Corros. Sci. 87 (2014) 334-343.

46. J. Izquierdo, G. Bolat, D. Mareci, C. Munteanu, S. González, R.M. Souto, Electrochemical behaviour of ZrTi alloys in artificial physiological solution simulating in vitro inflammatory conditions, Appl. Surf. Sci. 313 (2014) 259-266.

47. I.V. Branzoi, M. Iordoc, M. Codescu, Electrochemical studies on the stability and corrosion resistance of new zirconium-based alloys for biomedical applications, Surf. Inter. Anal. 40 (2008) 167-173.

48. D. Peng, X. Bai, H. Sun, B. Chen, Influence of aluminum ions implantation on corrosion behavior of Zircaloy-2 alloy in 1 M H2SO4, J. Wuhan Univ. Technol. Mater. Sci. Ed. 22 (2007) 394-399.

49. N. Nomura, Y.Tanaka, Suyalatu, R. Kondo, H. Doi, Y. Tsutsumi, T. Hanawa, Effects of phase constitution of Zr-Nb alloys on their magnetic susceptibilities, Mater. Trans. 50 (2009) 2466-2472.

50. Suyalatu, N. Nomura, K. Oya, Y. Tanaka, R. Kondo, H. Doi, Y. Tsutsumi, T. Hanawa, Microstructure and magnetic susceptibility of as-cast Zr-Mo alloys, Acta Biomater. 6 (2010) 1033-1038.

51. R. Kondo, R. Shimizu, N. Nomura, H. Doi, Suyalatu, Y. Tsutsumi, K. Mitsuishi, M. Shimojo, K. Noda, T. Hanawa, Effect of cold rolling on the magnetic susceptibility of Zr-14Nb alloy, Acta Biomater. 9 (2013) 5795-5801.

52. J. Pan, D. Thierry, C. Leygraf, Electrochemical impedance spectroscopy study of the passive oxide film on titanium for implant application, Electrochim. Acta 41 (1996) 1143-1153.

53. M. Aziz-Kerrzo, K.G. Conroy, A.M. Fenelon, S.T. Farrell, C.B. Breslin, Electrochemical studies on the stability and corrosion resistance of titanium-based implant materials, Biomaterials 22 (2001) 1531-1539.

54. N.T.C. Oliveira, E.A. Ferreira, L.T. Duarte, S.R. Biaggio, R.C. Rocha-Filho, N. Bocchi, Corrosion resistance of anodic oxides on the Ti-50Zr and Ti-13Nb-13Zr alloys, Corros. Sci. 51 (2006) 20682075.

55. J.R. Macdonald, Note on the parameterization of the constant-phase admittance element, Solid State Ionics 13 (1984) 147-149. 
56. T.P. Hoar, D.C. Mears, Corrosion-resistant alloys in chloride solutions: materials for surgical implants, Proc. Royal Soc. London A 294 (1966) 486-510.

57. T. Hanawa, Y. Tsutsumi, Calcium phosphate formation on titanium and zirconium and its application to medical devices, Bioceram. Dev. Appl. 1 (2011) D110119, 4 pages. doi:10.4303/bda/D110119

58. Z. Bastl, A. I. Senkevich, I. Spirovova, V. Vrtilkova, Angle-resolved core-level spectroscopy of Zr1Nb alloy oxidation by oxygen, water and hydrogen peroxide, Surf. Interf. Anal. 34 (2002) 477480.

59. A. Gomez Sanchez, M. Katunar, W. Schreiner, G. Duffó, S. Ceré, D.J. Schiffrin, Structure and dielectric properties of electrochemically grown $\mathrm{ZrO}_{2}$ films, Acta Chim. Slov. 61 (2014) 316-327.

60. A. Gomez Sanchez, W. Schreiner, G. Duffó, S. Ceré, Surface characterization of anodized zirconium for biomedical applications, Appl. Surf. Sci. 257 (2011) 6397-6405.

61. T. Hanawa, O. Okuno, H. Hamanaka, Compositional change in surface of Ti-Zr alloys in artificial bioliquid, J. Jpn. Inst. Met. 56 (1992) 1168-1173.

62. G. Jangg, R.T. Webster, M. Simon, Untersuchung über das Korrosionsverhalten von Zirkoniumlegierungen. IV. Das Lochfraßverhalten Zirkoniumlegierungen, Mater. Corros. 29 (1978) 16-26.

63. D.R. Knittel, A. Bronson, Pitting corrosion on zirconium-A review, Corrosion 40 (1984) 9-14.

64. M. Pourbaix, Atlas of Electrochemical Equilibria in Aqueous Solutions, NACE, Houston, TX, 1974. 


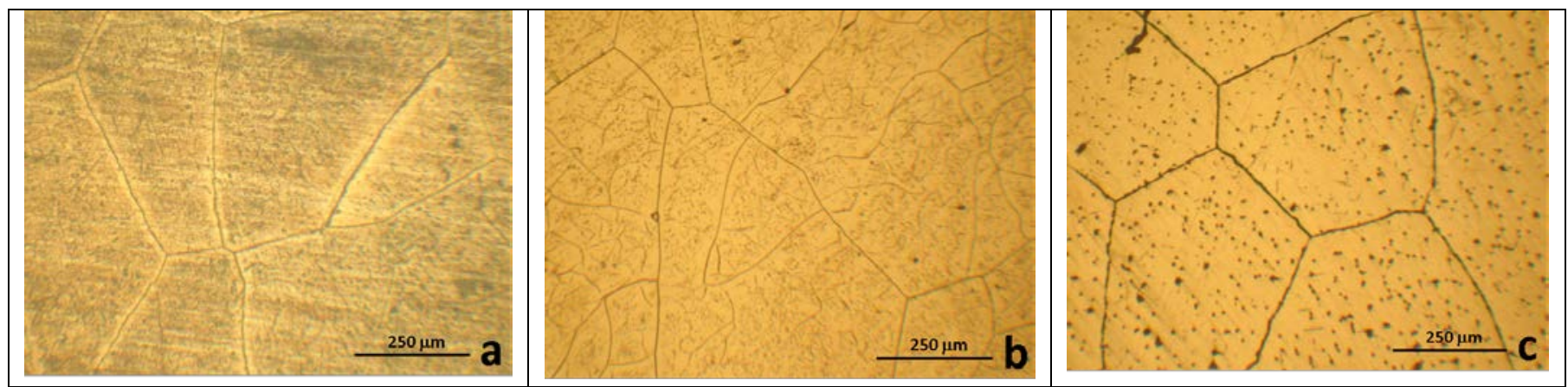

Figure 1. Optical micrographs showing the microstructure of the quaternary ZrTiNbAl alloys: a) Zr6Ti15Nb4Al, b) Zr32Ti15Nb4Al, c) Zr49Ti15Nb4Al.

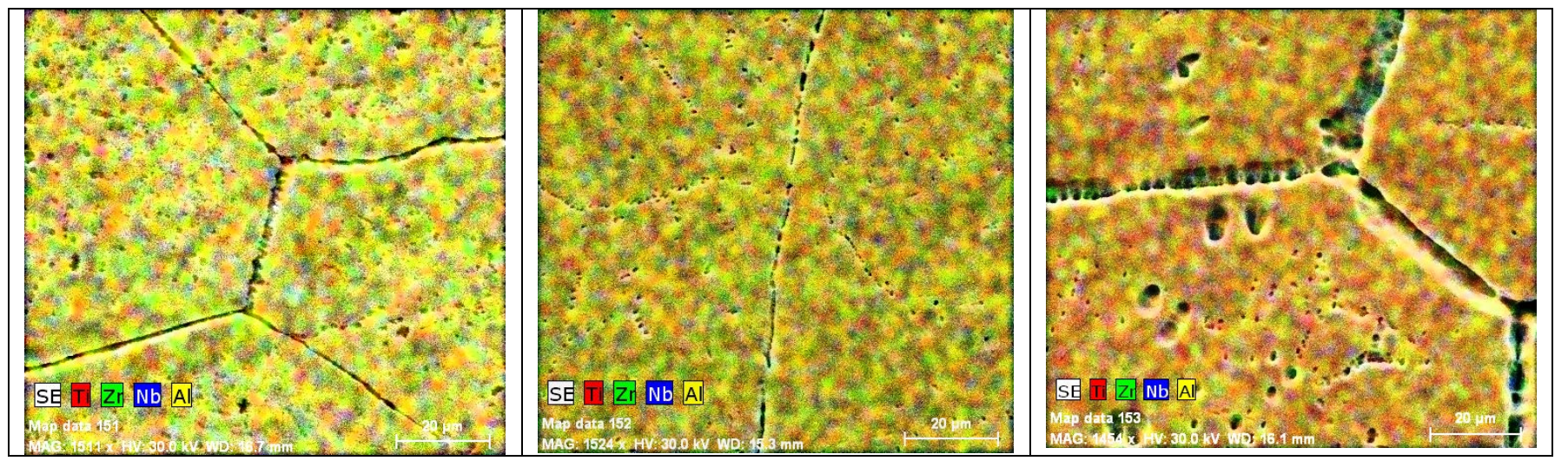

Figure 2. EDS elemental distribution maps of the quaternary ZrTiNbAl alloys: a) Zr6Ti15Nb4Al, b) Zr32Ti15Nb4Al, c) Zr49Ti15Nb4Al.

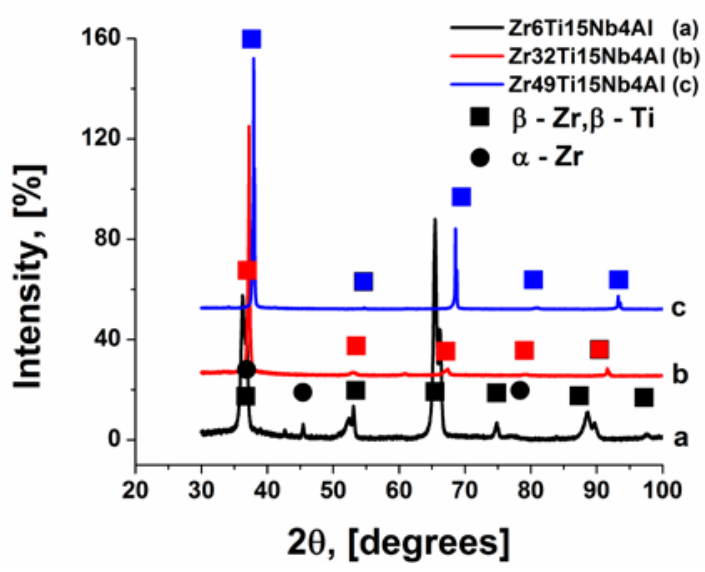

Figure 3. X-ray diffraction patterns of the quaternary ZrTiNbAl alloys. 


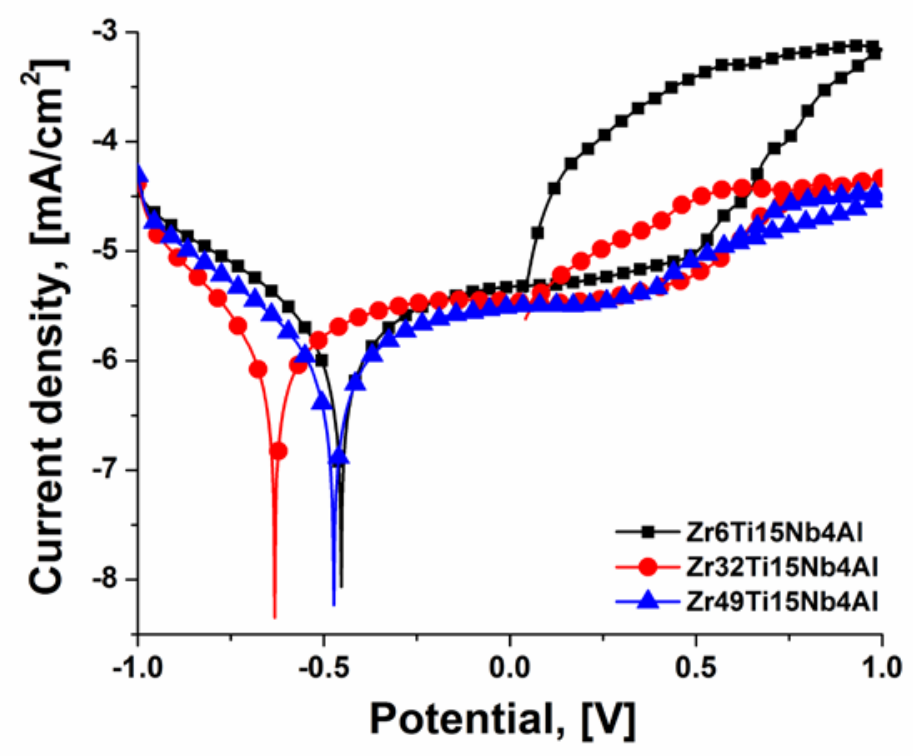

Figure 4. Linear potentiodynamic polarization curves measured for the quaternary ZrTiNbAl alloys after 7 days immersion in Ringer's solution at $37^{\circ} \mathrm{C}$.

\begin{tabular}{|c|c|}
\hline Frequency, [Hz] & 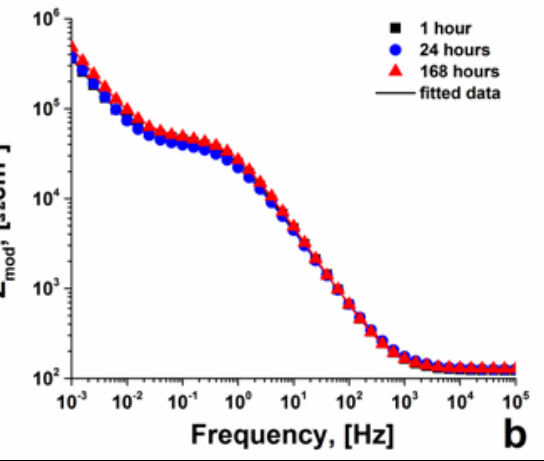 \\
\hline 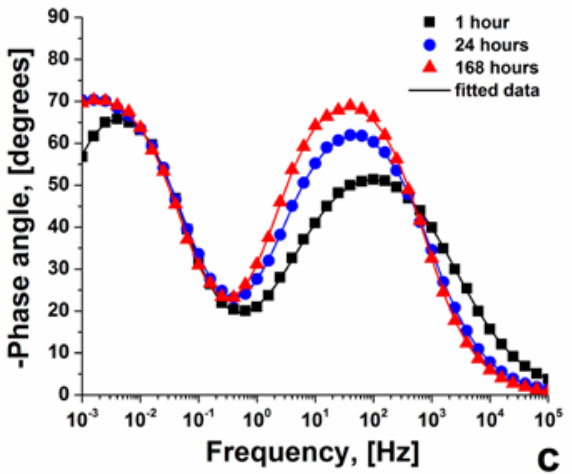 & 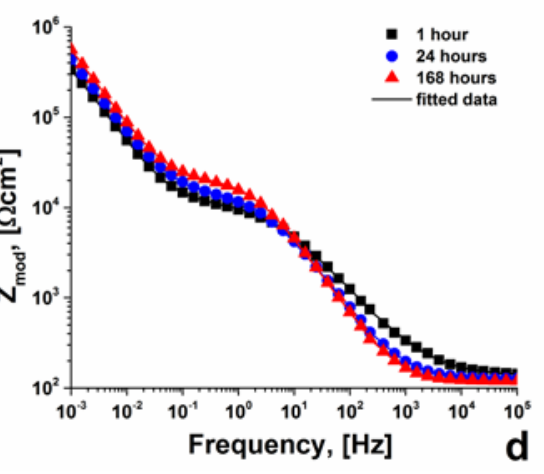 \\
\hline
\end{tabular}




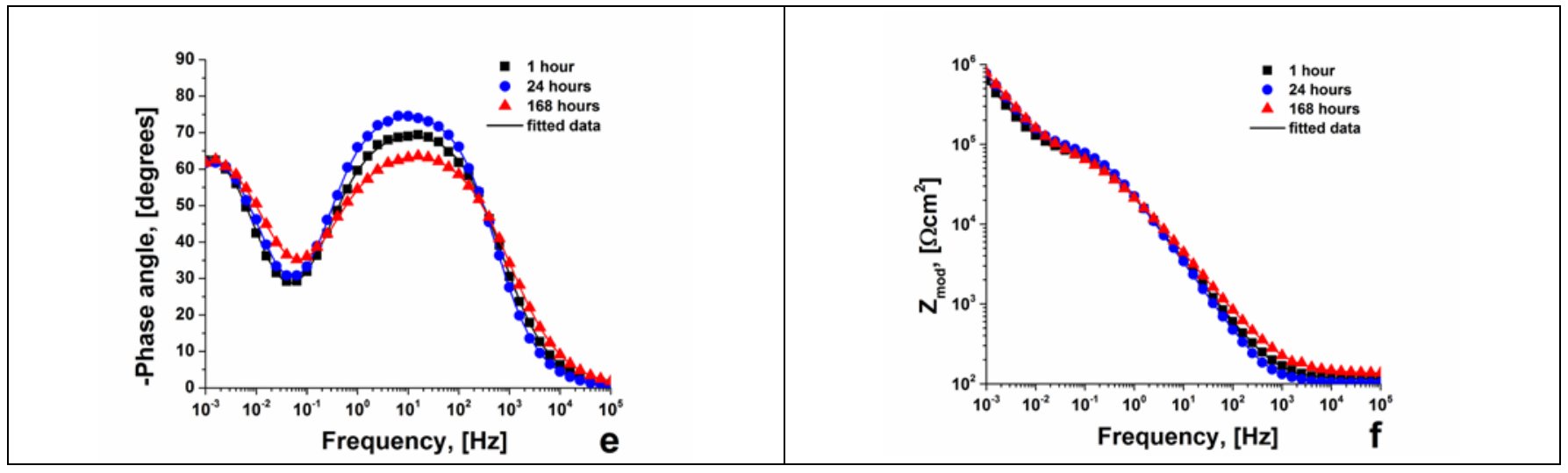

Figure 5. Bode impedance plots for the quaternary TiMoZrTa alloys immersed in Ringer's solution at $37^{\circ} \mathrm{C}$ for different immersion times. The solid lines and the discrete points correspond to the fitted and the measured data, respectively. Alloys: (a,b) Zr6Ti15Nb4Al, (c,d) Zr32Ti15Nb4Al, and (e,f) Zr49Ti15Nb4Al.

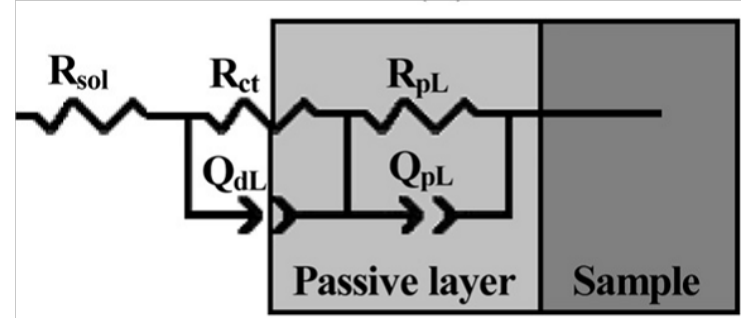

Figure 6. Equivalent circuit used to fit EIS data.

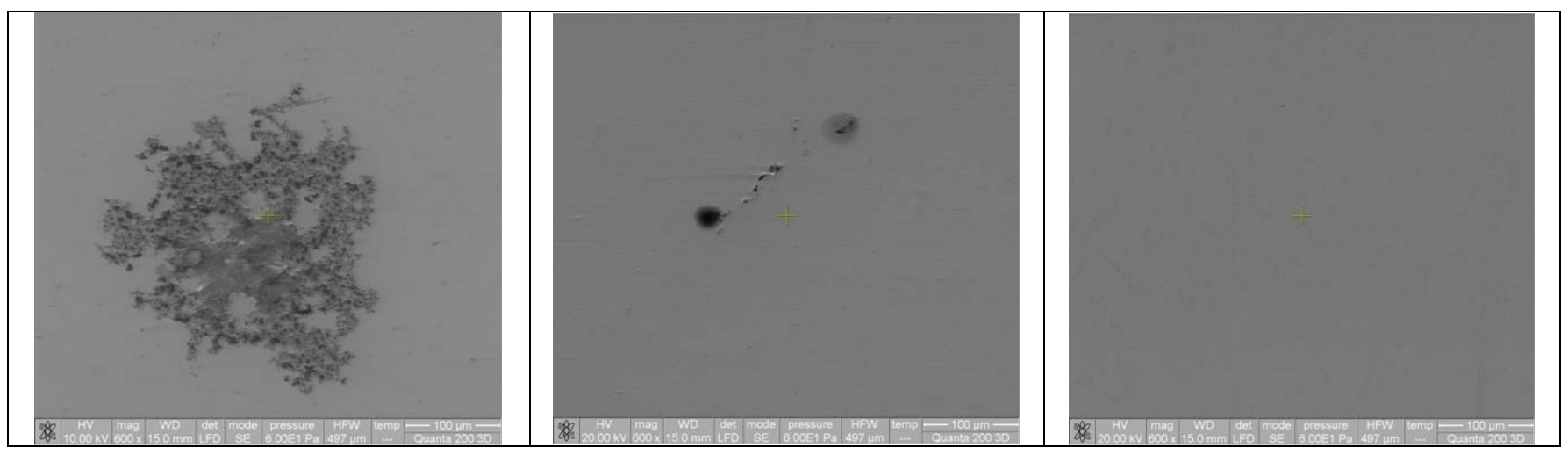

Figure 7. SEM observations of quaternary TiMoZrTa alloys retrieved from Ringer's solution at $37{ }^{\circ} \mathrm{C}$ after completing the linear potentiodynamic polarization tests shown in Figure 4. Alloys: (a,b) Zr6Ti15Nb4Al, (c,d) Zr32Ti15Nb4Al, and (e,f) Zr49Ti15Nb4Al. 
Table 1. Chemical composition of the quaternary ZrTiNbAl alloys.

\begin{tabular}{|c|c|c|c|c|r|c|}
\hline Alloy & Percentage / \% & $\mathrm{Zr}$ & $\mathrm{Ti}$ & $\mathrm{Nb}$ & \multicolumn{1}{c|}{$\mathrm{Al}$} & $\mathrm{Zr} / \mathrm{Ti}$ ratio \\
\hline \multirow{2}{*}{ Zr6Ti15Nb4Al } & weight & 75.77 & 6.01 & 14.74 & 3.48 & 12.61 \\
\cline { 2 - 7 } & atomic & 66.78 & 10.09 & 12.76 & 10.37 & 6.62 \\
\hline \multirow{2}{*}{ Zr32Ti15Nb4Al } & weight & 49.07 & 32.15 & 14.61 & 4.17 & 1.53 \\
\cline { 2 - 7 } & atomic & 35.36 & 44.15 & 10.34 & 10.16 & 0.80 \\
\hline \multirow{2}{*}{ Zr49Ti15Nb4Al } & weight & 32.94 & 47.69 & 15.42 & 3.95 & 0.69 \\
\cline { 2 - 7 } & atomic & 21.63 & 59.67 & 9.94 & 8.77 & 0.36 \\
\hline
\end{tabular}

Table 2. Average electrochemical parameters and average (standard deviation) values determined from potentiodynamic polarization curves for quaternary ZrNbTiAl alloys after 7 days immersion in Ringer's solution at $37^{\circ} \mathrm{C}$.

\begin{tabular}{ccccccccccc}
\hline \multirow{2}{*}{ Alloy } & $\begin{array}{c}\mathrm{Zr} / \mathrm{Ti} \\
\text { ratio }\end{array}$ & $\begin{array}{c}E_{\text {corr }} / \\
\mathrm{V}_{\mathrm{SCE}}\end{array}$ & $\begin{array}{c}j_{\text {corr }} / \mu \mathrm{A} \\
\mathrm{cm}^{-2}\end{array}$ & $\begin{array}{c}\left(j_{\text {pass }}\right)^{*} / \\
\mu \mathrm{A} \mathrm{cm}^{-2}\end{array}$ & $\begin{array}{c}E_{\mathrm{bd}} / \\
\mathrm{V}_{\mathrm{SCE}}\end{array}$ & $\begin{array}{c}E_{\mathrm{rp}} / \\
\mathrm{V}_{\mathrm{SCE}}\end{array}$ & $\begin{array}{c}\left(E_{\mathrm{bd}}-E_{\text {corr }}\right) \\
/ \mathrm{mV}\end{array}$ & $\begin{array}{c}\left(E_{\mathrm{bd}}-E_{\mathrm{rp}}\right) \\
/ \mathrm{mV}\end{array}$ & $\begin{array}{c}Q_{\mathrm{hyst}} / \mathrm{mC} \\
\mathrm{cm}^{-2}\end{array}$ \\
\hline \multirow{2}{*}{ Zr6Ti15Nb4Al } & \multirow{2}{*}{12.61} & -0.473 & 0.610 & 6.2 & +0.535 & +0.055 & 528 & 480 & 271.3 \\
& & $(0.011)$ & $(0.017)$ & $(0.2)$ & $(0.028)$ & $(0.012)$ & $(12.12)$ & $(14.53)$ & $(4.32)$ \\
Zr32Ti15Nb4Al & \multirow{2}{*}{1.53} & -0.629 & 0.455 & 3.9 & +0.610 & +0.045 & 674 & 565 & 19.7 \\
& & $(0.012)$ & $(0.015)$ & $(0.3)$ & $(0.040)$ & $(0.011)$ & $(11.53)$ & $(15.10)$ & $(3.34)$ \\
Zr49Ti15Nb4Al & 0.69 & -0.453 & 0.320 & 2.5 & & & & & - \\
& & $(0.010)$ & $(0.019)$ & $(0.3)$ & - & - & - & - & - \\
\hline
\end{tabular}

${ }^{*}$ at $0.30 \mathrm{~V}_{\mathrm{SCE}}$ 
Table 3. Electrochemical parameters extracted from impedance spectra (EIS) through modelling experimental data for quaternary ZrNbTiAl alloys in Ringer's solution at $37{ }^{\circ} \mathrm{C}$, after different immersion times, to the equivalent circuit containing two time constants shown in Figure 6.

\begin{tabular}{|c|c|c|c|c|c|c|c|c|}
\hline Alloy & $\begin{array}{l}\mathrm{Zr} / \mathrm{Ti} \\
\text { ratio }\end{array}$ & $\begin{array}{l}\text { Immersion } \\
\text { time / h }\end{array}$ & $\begin{array}{l}Q_{\mathrm{dL}} / \mathrm{mS} \\
\mathrm{cm}^{-2} \mathrm{~s}^{n}\end{array}$ & $n_{1}$ & $\begin{array}{c}R_{\mathrm{ct}} / \mathrm{k} \Omega \\
\mathrm{cm}^{2}\end{array}$ & $\begin{array}{c}Q_{\mathrm{pL}} / \mu \mathrm{S} \\
\mathrm{cm}^{-2} \mathrm{~s}^{n}\end{array}$ & $n_{2}$ & $\begin{array}{c}R_{\mathrm{pL}} / \\
\mathrm{M} \Omega \mathrm{cm}^{2}\end{array}$ \\
\hline \multirow{3}{*}{ Zr6Ti15Nb4Al } & \multirow{3}{*}{12.61} & 1 & 0.23 & 0.80 & 25 & 23 & 0.82 & 0.24 \\
\hline & & 24 & 0.18 & 0.81 & 47 & 22 & 0.82 & 0.33 \\
\hline & & 168 & 0.18 & 0.81 & 51 & 22 & 0.82 & 0.42 \\
\hline \multirow{3}{*}{ Zr32Ti15Nb4Al } & \multirow{3}{*}{1.53} & 1 & 0.18 & 0.81 & 47 & 22 & 0.82 & 0.31 \\
\hline & & 24 & 0.18 & 0.81 & 51 & 22 & 0.82 & 0.38 \\
\hline & & 168 & 0.18 & 0.81 & 52 & 21 & 0.82 & 0.45 \\
\hline \multirow{3}{*}{ Zr49Ti15Nb4Al } & \multirow{3}{*}{0.69} & 1 & 0.17 & 0.81 & 56 & 22 & 0.83 & 0.59 \\
\hline & & 24 & 0.17 & 0.82 & 62 & 19 & 0.83 & 0.71 \\
\hline & & 168 & 0.16 & 0.82 & 065 & 18 & 0.83 & 0.82 \\
\hline
\end{tabular}

